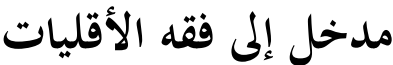

\section{(نظرات تأسيسية)}

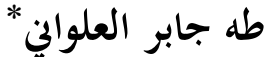

تحديدات

الفقه: لم تكن كلمة "فقه" - بالمعنى الاصطلاحي المعروف الآن - شائعة لدى الصدر الأول من هذه

الأمة، بل كانوا يستعملون كلمة "الفهم" لكنهم إذا وجدوا الأمر دقيق المسلك ربما عبروا عنه بـ "الفقه" بدلا من "الفهم". وقد أشار ابن خلدون في مقدمته إلى ذلك بقوله: (الفقه معرفة أحكام الله في أفعال المكلفين بالوجوب والحذر والندب والكراهة والإباحة، وهي متلقاة من الكتاب والسنة وما نصبه الشارع لمعرفتها من الأدلة، فإذا اسُُخرجت الأحكام من تلك الأدلة قيل لها "فقه").

ولم تكن تسمية "الفقهاء" شائعة أيضاً، بل كان أهل الاستباط من الصحابة يُعرفون باسم "القراء" تمييزًا لهم عن الأميين الذين لم يكونوا يقرأون. وفي هذا يقول ابن خلدون: (...ثم عظمت أمصار الاسلام، وذهبت الأمية من العرب بممارسة الكتاب، وتمكن الاستباط، ونما الفقه وأصبح صناعة وعلما، فبدلوا باسم

$$
\text { الفقهاء والعلماء من القراء).2 ودهبت العند }
$$

الأقليات: أما كلمة "الأقليات" فهي مصطلح سياسي جرى في العرف الدولي، يقصد به مجموعة أو فئات من رعايا دولة من الدول تنتمي من حيث العرق أو اللغة أو الدين إلى غير ما تنتمي إليه الأغلبية.

رئيس المجلس الفقهي لأمريكا الشمالية، رئيس جامعة العلوم الإسلامية والاجتماعية، فيرجينيا. 1 2 
وتشمل مطالب الأقليات -عادة- المساواة مع الأغلبية في الحقوق المدنية والسياسية، مع الاعتراف لها بحق الاختلاف والتميز في مجال الاعتقاد والقيم.

وتتأسس قيادات للأقليات -في كثير من الأحيان- تحاول التعبير عن أعضاء الأقلية من خلال الأمور

1- إعطاء تفسير للأقلية التي تنتمي إليها جذورها التاريخية، ومزاياها ومبررات وجودها، لتساعد الأقلية على الإجابة عن سؤال "من نحن"؟ وضمنًا عن سؤال "ماذا نريد"؟ 2- بحميع عناصر الأقلية وإقامة روابط بينها. 3- تبني الرموز الثقافية المعبرة عن خصوصية الأقلية. 4- تحقيق أمن معاشي وتكافل اجتماعي كما في الحالة اليهودية.

يثير الحديث عن فقه الأقليات عددًا من الأسئة المنهجية، منها: إلى أي العلوم الشرعية أو النقلية ينتمي هذا الفقه؟ بأي العلوم الاجتماعية يمكن لهذا العلم أن يتصل، وما مقدار تفاعله مع كل منها. لماذا سمي بـ "فقه الأقليات"؟ وإلى أي مدى تعتبر هذه التسمية دقيقة؟ كيف نتعامل مع القضايا التي يثيرها وجود المسلمين بكثافة خارج المحيط الجغرافي والتاريخي الإسلامي؟ ولإجابة على هذه التساؤلات نقول: لا يمكن إدراج "فقه الأقليات" في مدلول "الفقه" كما هو شائع الآن - أي فقه الفروع - بل الأولى إدراجه ضمن "الفقه" بالمعنى العام الذي يشمل كل جوانب الشرع 
اعتقادًا وعملاً، بالمعنى الذي قصده النبي صلى الله عليه وسلم في قوله: "من يرد الله به خيرًا يفقهه في

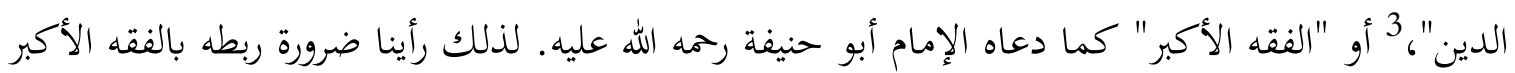
وضعًا للفرع في إطار الكل، وبتاوزًا للفراغ التشريعي أو الفقهي. إن فقه الأقليات هو فقه نوعي يراعي ارتباط الحكم الشرعي بظروف الجماعة، وبالمكان الذي تعيش فيه، فهو فقه جماعة محصورة لها ظروف خاصة يصلح لها ما لا يصلح لغيرها. ويمتاج متناوله إلى ثقافة في بعض العلوم الاجتماعية، عامة وعلم الاجتماع والاقتصاد والعلوم السياسية والعلاقات الدولية خاصةً.

\section{تفكيك السؤال}

وإذا ثار سؤال له صلة بفقه الأقليات على لسان فرد، أو دار على ألسنة جماعة، فإن المفتي المعاصر يحتاج إلى بحاوز الموقف الساذج البسيط الذي يحصر الأمر بين سائل وبجيب: سائل يعوزه الاطلاع الشرعي، وبجيب يعتبر الأمر منتهيًا عند حدود الاستفتاء والإفتاء. فهذا موقف غير علمي ورثناه عن عصور التقليد، وكرسته عقلية العوام التي استسهلت التقليد واستنامت له.

والمطلوب تبني موقف علمي يبحث في خلفية السؤال والسائل، والعوامل الاجتماعية التي ولدت السؤال وأبرزت الإشكال، وهل هو سؤال مقبول بصيغته المطروحة، أم يتعين رفضه بهذه الصيغة، وإعادة صياغته في صورة إشكال فقهي، ثم معالجته في ضوء رؤية شاملة تستصحب القواعد الشرعية الكلية، والمبادئ القرآنية الضابطة، وتراعي غايات الإسلام في الانتشار والتمكين على المدى البعيد.

ومن هنا نستطيع أن نفهم في القرآن الجميد عن أمثلة معينة من شأن إثارتا والإجابة عنها أن تؤدي إلى مشكلات اجتماعية خطيرة، لأن تلك الأسئلة صاغتها ظواهر سلبية، فإذا أجيب عنها في ذلك السياق استحكمت تلك الظواهر وتمكنت. كما نستطيع في ضوء ذلك فهم في الرسول صلى الله عليه وسلم عن

$$
\text { "قيل وقال وكثرة السؤال..." - مقال }
$$

$$
3
$$


فإذا سأل سائل - مثلا - هل "يجوز" للأقليات المسلمة أن تشارك في الحياة السياسية في البلد المقيمة فيه، بما يحفظ لها حقوقها، ويمكنها من مناصرة المسلمين في بلدان أخرى، ويبرز قيم الاسلام وثقافته في البلد المضيف؟ فإن الفقيه الواعي بعالمية الاسلام وشهادة أمته على الناس، وبالتداخل في الحياة الدولية المعاصرة لن يقبل السؤال بهذه الصيغة، بل سينقله من منطق الترخص السلبي إلى منطق الوجوب والإيجابية، انسجاماً مع ما يعرف من كليات الشرع وخصائص الأمة والرسالة.

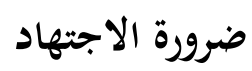

لقد استوطن الإسلام في العقود الأخيرة بلدانا كثيرة لا تدخل ضمن حيزه التاريخي، وصار وجوده ناميا في تلك البلدان، وبدأ المسلمون يواجهون واقعا جديدا يثير أسئلة كثيرة جدًا تتجاوز القضايا التقليدية ذات الطابع الفردي المتعلقة بالطعام المباح واللحم الحلال وثبوت الهلال والزواج بغير المسلمة، إلى قضايا أكبر دلالة وأعمق أثرًا ذات صلة بالهوية الإسلامية، ورسالة المسلم في وطنه الجديد، وصلته بأمته الإسلامية، ومستقبل الإسلام وراء حدوده الحالية.

وربما حاول البعض الإجابة على هذا النمط من الأسئلة بمنطق "الضرورات" و"النوازل" ناسين أنه منطق هش لا يتسع لأمور ذات بال. وربما واجه المسلم فوضى في الإفتاء: فهذا الفقيه يُحِل، وذاك يحرِّم،

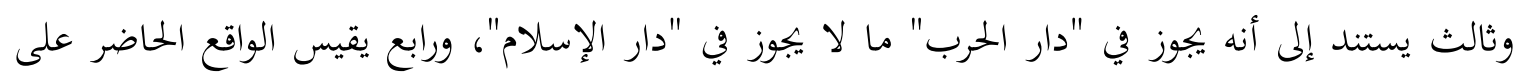
الماضي الغابر قياسا لا يأبه بالفوارق النوعية الهائلة بين مجتمع وآخر، وبين حقبة تاريخية وأخرى؟ بل لا يأبه بالقواعد الأصولية القاضية بمنع قياس فرع على فرع.

فتكون النتيحة المنطقية لهذا المنطلق المنهجي الخاطئ إيقاع المسلمين في البلبلة والاضطراب، وتحجيم دورهم المرتقب، والحكم عليهم بالعزلة والاغتراب، وإعاقة الحياة الإسلامية، وفرض التخلف عليها، وإظهار الإسلام بمظهر العاجز عن مواجهة أسئلة الحضارة والعمران المستنير في زماننا هذا. 
والحق أن مشكلات الأقليات المسلمة لا يمكن أن تواجه إلا باجتهاد جديد، ينطلق من كليات القرآن الكريم وغاياته وقيمه العليا ومقاصد شريعته ومنهاجه القويم، ويستنيربما صح من سنة وسيرة الرسول صلى الله عليه وسلم في تطبيقاته للقرآن وقيمه وكلياته.

\section{تجاوز الفقه الموروث}

أما الفقه الموروث في بجال التنظير لعلاقة المسلمين بغيرهم فهو - على ثرائه وتنوعه وغناه وتشعبه قد أصبح اغلبه جزءًا من التاريخ، لأسباب تتعلق بالمنهج، وأخرى بتحقيق المناط.

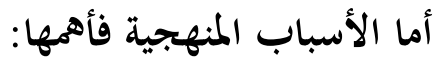

أولاً: لم يرتب بعض فقهائنا الأقدمين مصادر التشريع الترتيب الصحيح الذي يعين على حسن الاستباط، والذي يقضي باعتبار القرآن الكريم أصل الأصول، ومنبع التشريع، والمصدر التأسيسي المهيمن على ما سواه، والمقدم عليه عند التعارض. واعتبار السنة النبوية مصدرًا بيانياً ملزماً يكمّل القران ويفصله ويتبعه.

ثانياً: لم يأخذ أكثر فقهائنا عالمية الإسلام بعين الاعتبار في تنظيرهم الفقهي لعلاقة المسلمين بغيرهم، بل عبروا عن نوع من الانطواء على الذات لا يتناسب مع حماس الرسالة الخاتمة والأمة الشاهدة.

ثالثاً: تأثر الفقهاء بالعرف التاريخي السائد في عصرهم حول التقسيم الدولي للعالم، فضاقت نظرقم للموضوع، وابتعدوا عن المفهوم القرآي للجغرافيا. 
أولاً: لم يعتد المسلمون في تاريخهم -بعد عصرالرسالة- على اللجوء إلى بلاد غير إسلامية طلبًا لحق

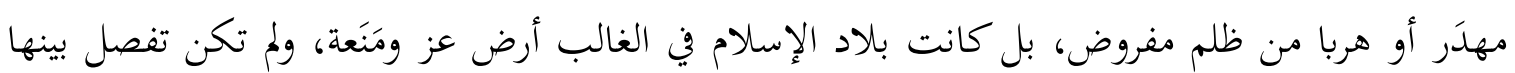

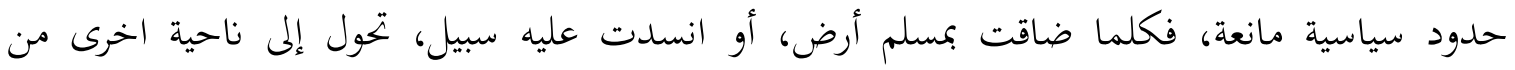
الامبراطورية الاسلامية الفسيحة، دون أن يحس بغربة، أو تعتريه مذلة.

ثانياً: لم تكن فكرة المواطنة - كما نفهمها - اليوم موجودة في العالم الذي عاث فيه فقهاؤنا الأقدمون، وإغنا كان هناك نوع من الانتماء الثقاف لحضارة معينة، أو الانتماء السياسي إلى إمبراطورية معينة يعتمد

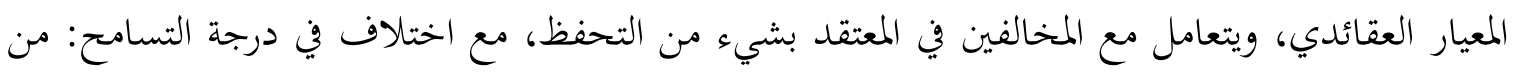
محاكم التفتيش الأسبانية إلى الذمة الإسلامية.

ثاثلاً: لم تكن الإقامة في بلد غير البلد الأصلي تُكسب حق المواطنة بناء على معايير ثابتة، مثل الميلاد

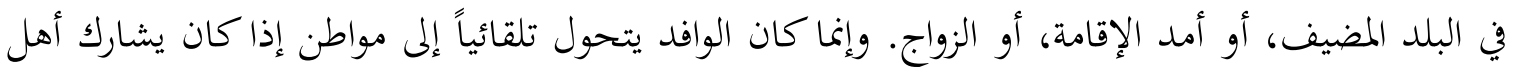

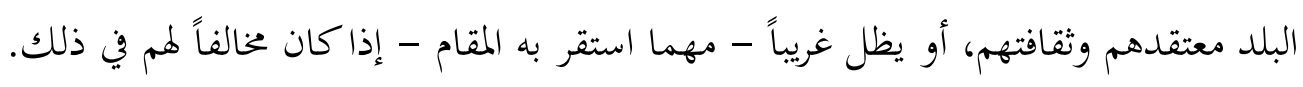

رابعاً: لم يكن العالم القديم يعرف شيئاً اسمه القانون الدولي أو العلاقات الدبلوماسية، اللذان يختِّمان

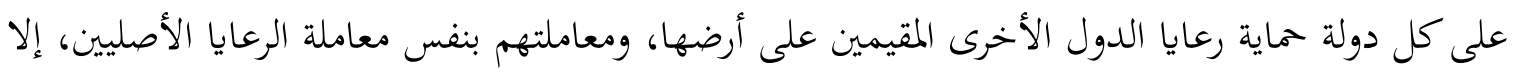
في بعض الأمور الخاصة التي تقتضي حقوق المواطنة التميز فيها.

خامساً: كان منطق القوة هو الغالب على العلاقة بين الامبراطوريات القديمة - بما فيها الامبراطورية

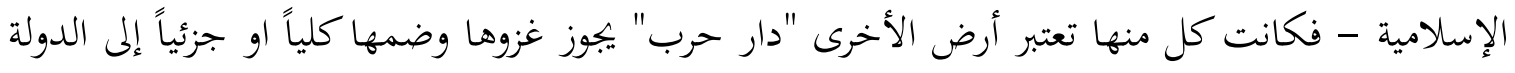
الغالبة، إذ من طبيعة الامبراطوريات أها لا تعرف حدوداً إلا حيث تتعسر على جيوشها مواصلة الزحف. سادساً: لم يعش فقهاؤنا الوحدة الأرضية التي نعيشها اليوم، حيث تتداخل الثقافات، وتعيش الأمم في

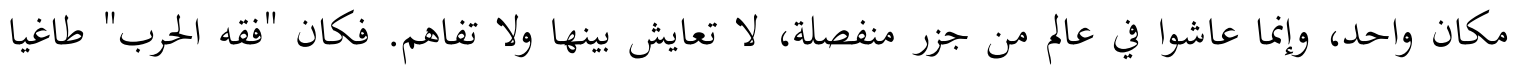
بهكم مقتضيات الواقع يومذاك. وما نتاجه اليوم هو "فقه التعايش" في واقع ختخلف كمَّا ونوعاً. 
سابعاً: كان بعض الفقهاء الأقدمين والمتأخرين يعبرون بفتاواهم عن نوع من المقاومة وردة الفعل على واقع مخصوص يختلف عن واقعنا، وفي هذا الإطار يمكن أن ندرج كتاب ابن تيمية "اقتضاء الصراط المستقيم مخالفة أهل الجحيم" وفتاوى علماء الجزائر في صدر هذا القرن بتحريم حمل الجنسية الفرنسية. فهذه الكتب والفتاوى جزء من ثقافة الصراع التي لا تحتاجها الأقليات الإسلامية.

\section{نحو أصول لفقه الأقليات}

لذلك نقترح على أهل العلم جملة من المحددات المنهجية أو "الأصول" التي ترى ضرورة اعتمادها من قبل المفتي في فقه الأقليات، باعتبار خصوصية هذا الفقه، وباعتبار أن كل "فقه" يحتاج إلى أصول:

1- اكتشاف الوحدة البنائية في القرآن، وقرائته باعتباره معادلاً للكون وحركته، واعتبار السنّة النبوية الصادرة عن المعصوم صلى الله عليه وسلم تطبيقاً لقيم القرآن، وتنزيلاً لها في واقع معين، والنظر إليها كوحدة في ذاتا، متحدة مع القرآن، بيانا له وتنزيلاً لقيمته في واقع نسبي محدد.

2- الاعتراف بحاكمية الكتاب الكريم وأسبقيته، وأنه قاض على ما سواه بما في ذلك الأحاديث

والآثار. فإذا وضع الكتاب الكريم قاعدة عامة - مثل مبدأ "البر والقسط" في علاقة المسلمين بغيرهم ووردت أحاديث أو آثار يتناقض ظاهرها مع هذا المبدأ: كالمزاحمة في الطريق، أو عدم رد التحية بمثلها أو أحسن منها، تعين الأخذ بما في الكتاب، وتأوِّل الأحاديث والآثار إن أمكن تأوُّها، أو ردُّها إن لم يمكن ذلك.

3- الانتباه إلى أن القرآن المجيد قد استرجع تراث النبوات، وقام بنقده وتنقيته من كل ما أصابه من تحريف، وأعاد تقديمه منقحًا خاليًا من الشوائب، وذلك لتوحيد المرجعية للبشرية. ذلك هو تصديق القرآن لميزاث النبوة كله وهيمته عليه.

4- تأمل الغائية في القرآن الكريع: وهي التي تربط الواقع الانساني المرئي باللامرئي (عالم الغيب). وتزيل فكرة العبث والمصادفة، وذلك ما يمكن من إدراك وتفسير العلاقات بين الغيب والشهادة، وبين النص 
المطلق -وهو القرآن- والواقع الإنساني، وتوجد نوعاً من الكشف عن الفارق الدقيق بين إنسانية الإنسان وبين فرديته. فالإنسان باعتبار فرديته مخلوق نسبي، وهو باعتبار إنسانيته مخلوق كوني مطلق.

5- الانتباه إلى أهمية البعدين الزماني والمكاني في كونية الحنق الإنساني. ففي الجانب الزماني أكد القرآن ذلك البعد بتعقيبه على تحديد الأشهر باثني عشر شهرا ومنع النسيء فعدَّهما جزءًا من الدين القيّم. وفي الجانب المكاني جعل لنا أرضًا محرمة وأرضًا مقدسة، وأرضًا ليست كذلك. وفي هذا الإطار يمكن أن تفهم فكرة امتداد الإنسان منذ خلق آدم وحواء حتى دخول الجنة أو النار والعياذ بالله. إنّ ذلك الامتداد هو الذي يربط بين كونية القرآن وكونية الإنسانية.

6- الانتباه إلى وجود منطق قرآني كامن قواعده مبثوثة في ثنايا الكتاب، وأن الإنسان قادر - بتوفيق الله عز وجل - على الكشف عن قواعد ذلك المنطق، لتساعده في تسديد عقله الذاتي وترشيد حركته. كما أنّ هذه القواعد ذاها يمكن أن تشكل قوانين تعصم العقل الموضوعي من الشذوذ والشرود والخطأ والانحراف، وهذا المنطق القرآي يستطيع أن يوجد قاعدة مشتركة للتفكير بين البشر تساعدهم على الخروج من دوائر هيمنة العقل الذاتي القائم على مسلّمات تقليد الآباء وتراثهم، وما يتبع ذلك من مسلّمات قبليّة يستطيع المنطق القرآي أن يخرجهم منها إلى المنطق الاستدلالي أو البرهاني.

7- الالتزام بالمفهوم القرآي للجغرافيا: فالأرض لله والاسلام دينه، وكل بلد هو "دار إسلام" بالفعل في الواقع الحاضر، أو "دار إسلام" بالقوة في المستقبل الآتي. والبشرية كلها "أمة إسلام": فهي إما "أمة ملة" قد اعتنقت هذا الدين، أو"أمة دعوة" نحن ملزمون بالتوجه إليها لدخوله.

8- اعتبار عالمية الخطاب القرآي: فالخطاب القرآي يخالف خطابات الأنبياء السابقين التي كانت خطابات اصطفائية موجهة إلى أمم مصطفاة أو قرى مختارة. أما الخطاب القرآني فقد تدرّج من الرسول صلى الله عليه وسلم عشيرته الأقربين، إلى أم القرى ومن حولها، ثم إلى الشعوب الأميّة كلها، ثم إلى العالم كله. وبذلك صار هو الكتاب الوحيد الذي يستطيع أن يواجه الحالة العالمية الراهنة. إن أي خطاب يوجه إلى عالم اليوم لابد أن يقوم على قواعد مشتركة وقيم مشتركة، وأن يكون منهجيًا، أي خطابًا قائمًا على قواعد 
ضابطة للتفكير الموضوعي، وليس هناك كتاب على وجه الأرض يستطيع أن يوفر هذه الشروط إلا القرآن البجيد ذاته.

9- التدقيق في الواقع الحياتي بمركباته المختلفة باعتباره مصدرًا لصياغة السؤال والإشكال الفقهي، أو "تنقيح المناط" كما يقول الأقدمون. وما لم يُفهم هذا الواقع بمركباته كلها فإنه من المتعذر صياغة الإشكال الفقهي بشكل ملائم بحيث مككن الذهاب به إلى رحاب القرآن الكريم لثويره واستنطاقه الجواب. ففي العصر النبوي كان الواقع يصوغ السؤال فينزّل الوحي بالجواب، أما في عصرنا هذا فإنّ الوحي بين أيدينا، ونحتاج إلى أن نتقن صياغة إشكالياتنا وأسئلتنا لنذهب بها إلى القرآن الكريم ونستنطقه الجواب عنها، ونستنطق من سنّة الرسول صلى الله عليه وسلم فقه التنزيل ومنهجية الربط بين النص المطلق والواقع النسبي المتغيّر نوعًا وكمًا.

10- دراسة القواعد الأصولية بكل تفاصيلها بما فيها مقاصد الشريعة، وذلك في محاولة للاستفادة بها في صياغة وبلورة مبادئ فقه الأقليات المعاصر. ولابد من تكييف الدراسة للمقاصد، وربطها بالقيم العليا الحاكمة، وملاحظة الفروق الدقيقة بين مقاصد الشارع ومقاصد المكلفي.

11- الإقرار بأن فقهنا الموروث ليس مرجعا للفتوى أو صياغة الحكم في مثل هذه الأمور، بل هو سوابق في الفتوى وفي القضاء يمكن الاستئناس بها واستخلاص منهجيتها والبناء على ما يصلح البناء عليه منها. فإن وُجد في كلام الاقدمين ما يناسب الواقع، ويقارب روح الشرع استؤنس به - تأكيدا للتواصل والاستمرارية بين أجيال الأمة - دون أن يُرفع إلى مستوى النص الشرعي، أو يعتبر فتوى في القضية المتناولة. ولا غضاضة إذا كان سلفنا لا يملكون جوابًا لإشكاليات لم يعيشوها، ووقائع لم تخطر لهم على بال.

اختبار الفقه في الواقع العملي: فلكل حكم فقهي أثر في الواقع قد يكون إيبابيًّ إذا كان استخلاص الفتوى ثم وفقا لقواعد منهجية ضابطة، وقد يحدث خلل في أي مستوى من المستويات، يكون الأثر المترتب على الفتوى أو على الحكم في الواقع أثرًا سلبيًا، فتجب مراجعته للتأكد والتحرير. وبذلك تكون عملية استنباط الأحكام وتقديم الفتاوى عبارة عن جدل متواصل بين الفقه والواقع، فالواقع مختبر يستطيع أن يبيّن لنا ملاءمة الفتوى أو حرجها. 


\section{الأسئلة الكبرى}

إن الفقيه الذي سيتناول فقه الأقليات يحتاج إلى التأمل في الأسئلة الكبرى التي يثيرها هذا الموضوع، ليحسن تنقيح المناط، ويصيب حكم الله تعالى في الموضوع ما استطاع، ومن هذه الأسئلة:

كيف يجيب أبناء الأقلية بدقة تعكس الخاص بهم والمشترك مع الآخرين عن السؤالين: من نحن؟ وماذا

ما النظم السياسية التي تعيش "الأقلية" في ظلها؟ هل هي دمقراطية أم وراثية، أم عسكرية؟

ما طبيعة الأكثرية التي تعيش الأقلية بينها، أهي أكثرية متسلطة تستبد بها مشاعر الهيمنة والتفرد؟ أم هي أكثرية تعمل على تحقيق توازن متحرك تحكمه قواعد مدروسة تقدم ضمانات للأقليات؟ وما حجم تلك الضمانات؟ وما آليات تشغيلها؟

ما حجم هذه الأقلية التي يراد التنظير الفقهي هلا على المستويات المختلفة: البشرية والثقافية

$$
\text { والاقتصادية والسياسية؟ }
$$

ما طبيعة التداخل المعاشي بين أطراف المجتمع؟ هل تتداخل الأقلية مع الأكثرية في الموارد والصناعات والمهن والأعمال (الحقوق والواجبات) أو أنّ هناك تمايزًا من خلال سياسات تسعى إلى إيجاد وتكريس

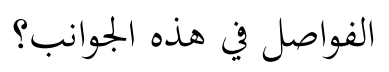

ما طبيعة الجغرافيا السكانية؟ هل هناك تداخل؟ أم أنّ هناك فواصل وعوازل طبيعية أو مصطنعة؟ وهل هناك موارد طبيعية خاصة بالأقلية أو بالأكثرية؟ أم أن هناك مشاركة في ذلك؟

هل الأقلية تتمتع بعمق حضاري وهوية ثقافية تؤهل - ولو في المدى البعيد- للهيمنة الثقافية؟ وما أثر

$$
\text { ذلك لدى الأكثرية؟ }
$$

هل للأقلية امتداد خارج حدود الوطن المشترك، أو هي أقلية مطلقة لا امتداد لها؟ وما تأثير ذلك في 
هل للأقلية فعاليّات وأنشطة تحرص على التميّز بها؟ وما تلك الفعاليّات؟

هل تستطيع ممارستها بشكل عفوي وتلقائي، أو لابد من قادة ومؤسسات تساعدها على تنظيم ممارستها لتلك الفعاليات؟

ما الدور الذي تلعبه هذه المؤسسات أو التنظيمات أو القيادات في حياة الأقلية، هل هو تسليط مزيد من الضوء والتركيز على هويتها الثقافية؟

هل تصبح هذه المؤسسات وسيلة لتكوين شبكة من المصالح، قد تساعد على استمرار التركيز على خصوصيات الأقلية، وإقناعها بأن الخصوصية الثقافية هي المبرر والمسوغ لاعتبارها أقلية؟ هل ستوصل هذه المؤسسات -دون أن تشعر - أبناء الأقلية إلى طرح سؤال خطير حول مدى قيمة وأهمية هذه الخصوصيات، ولم لا نتجاوزها فنريح ونستريح، أو نعمل على إقناع الأكثرية بها؟! إذا كانت الأقلية تمثل مزيجًا من جذور تاريخية وعرقية محتلفة، فكيف يمكن تحديد معالم هويتها الثقافية دون الوقوع في خطر دفع جمهورها إلى حالة الذوبان في الآخر أو الانكفاء على الذات؟ كيف يمكن إيجاد الوعي الضروري لتجاوز الأقلية ما قد يحدث من ردود أفعال لدى الأكثرية، وامتصاص سلبيات هذه الأمور دون التفريط بإيجابياها؟ كيف يمكن إلغاء الفعايات المشتركة بين الأقلية والأكثرية؟ وما المستويات التي يجب ملاحظتها في هذه

كيف يمكن الوصل والفصل بين مقتضيات المحافظة على الهوية الثقافية "الخاصة" والهوية الثقافية "المشتركة"

ماذا على الأقلية أن تفعل لتمييز ما يمكن أن يتحول إلى مشترك من أجزاء ثقافتها؟ وما الذي تستطيع أن تتبناه من المشترك المأخوذ من ثقافة الأكثرية؟ وما دور الأكثرية في هذا؟ 
وبناء على هذه التوضيحات المتعلقة بالمنهج، وبتحقيق المناط، وبحجم الأسئلة المثارة، نستطيع التأكيد على أن الكثير من الاجتهادات الفقهية القديمة التي نشأت في عصر الإمبراطوريات لن تسعفنا كثيراً في تأسيس فقه أقليات معاصر، مح احترامنا لتلك الاجتهادات، وإقرارنا بفائدة البعض منها في حدوده الزمانية والمكانية. بل يلزمنا الرجوع إلى الوحي والتجربة الإسلامية الأولى، مع الاستئناس بأقوال بعض المجتهدين الذين عبروا عن الروح الإسلامية، وتحرووا من قيود التاريخ أكثر من غيرهم، دون اعتبار أقوالهم مصدراً مؤسِسِاً

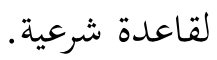

\section{قاعدة في علاقة المسلمين بغيرهم}

لقد تضمنت آيتان من القران الكريم قاعدة ذهبية في علاقة المسلمين بغيرهم، هما قول الله تعالى: ينهاكم الله عن الذين لم يقاتلوكم في الدين ولم يخرجوكم من دياركم أن تبروهم وتقسطوا إليهم إن الله يحب المقسطين. إنا ينهاكم الله عن الذين قاتلوكم في الدين وأخرجوكم من دياركم وظاهروا على إخراجكم أن تولوهم ومن يتولهم فأولئك هم الظالمونه.

قال ابن الجوزي: "هذه الآية رخصة في صلة الذين لم ينصبوا الحرب للمسلمين، وجواز برهم، وإن

كانت الموالاة منقطعة عنهم".

وقال القرطبي: "هذه الآية رخصة من الله تعالى في صلة الذين لم يعادوا المؤمنين ولم يقاتلوهم، قوله

تعالى:

وأكد ابن جرير على عموم الآية في غير المسلمين من كل الأديان والملل والنحل، فقال: "وأولى الأقوال

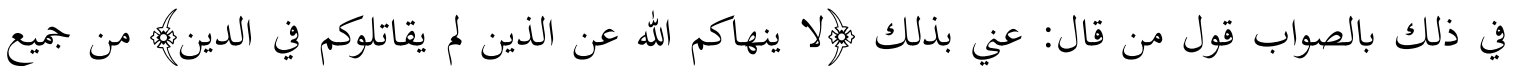

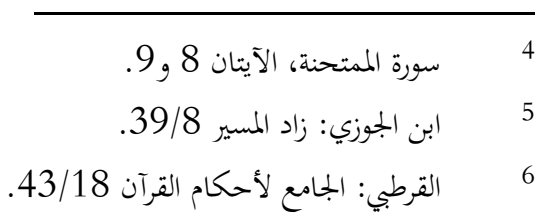


أصناف الملل والأديان أن تبروهم وتصلوهم وتقسطوا إليهم. إن الله عز وجل عمّ بقوله هوالذين لم يقاتلوكم في الدين ولم يخرجوكم من دياركمه مجيع من كان ذلك صفته، فلم يخصص به بعضاً دون بعض". 7

وفسَّر جلّ المفسرين"القسط" الوارد في الآية بأنه العدل، لكن القاضي أبو بكر بن العربي أعطاه معنى

آخر، باعتبار أن العدل واجب على المسلم بتحاه الجميع أعداء وأصدقاء، لقوله تعالى: هورولا يجرمنكم شنآن قوم على أن لا تعدلوا، اعدلوا هو أقرب للتقوى (المائدة: 8). أما القسط في هذه الآية فهو - عند ابن العربي - الإحسان بالمال: "وتقسطوا إليهم": أي تعطوهم قسطاً من أموالكم على وجه الصلة، وليس يريد به العدل، فإن العدل واجب في من قاتل وفي من لم يقاتل، قاله ابن العربي. 8

لقد حددت هاتان الآيتان الأساس الأخلاقي والقانوني الذي يجب أن يعامل به المسلمون غيرهم، وهو البر والقسط لكل من لم يناصبهم العداء. وكل النوازل والمستجدات ينبغي محاكمتهما إلى ذلك الأساس. وما كان للعلاقة بين المسلمين وغيرهم أن تخرج عن الإطار العام والهدف الأسمى الذي من أجله أنزل الله الكتب وأرسل الرسل، وهو قيام الناس بالقسط: واهملد أرسلنا رسلنا بالبينات وأنزلنا معهم الكتاب والميزان ليقوم الناس بالقسط مُ (الحديد: 25). فقاعدة "القيام بالقسط" قاعدة مطرّدة، سواء تعلق الأمر بإعطاء غير المسلمين حقوقهم، أو سعي المسلمين إلى أخذ حقوقهم.

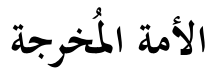

وبينت آية من الكتاب الكريم اثنتين من خصائص أمة التوحيد هما: الخيرية والإخراج، قال تعالى: أو كنتم خير أمة أخرجت للناس (ال عمران: 110) فهذه الآية تدل على أن خيرية هذه الأمة تتمثل في أن الله تعالى أخرجها للناس لتخرجهم من الظلمات إلى النور. فهي أمة يُخرجة (بفتح الراء) غخرِجة (بكسره) لا تنفك خيريتها عن دورها الرسالي على هذء الأرض المتمثل في "إخراج الناس من عبادة الله تعالى" كما لخصه ابن عامر رضي الله عنه أمام كسرى.

7 8 
وقد بين المفسرون من السلف ومن المتأخرين على حد السواء الارتباط بين معنى الخيرية والإخراج: عن عكرمة في تفسير الآية قال: "خير الناس للناس، كان من قبلكم لا يأمن هذا في بلاد هذا، ولا هذا في بلاد هذا، فكلما (=أينما) كنتم أمِن فيكم الأمر والأسود، فأنتم خير الناس للناس"، و وقال ابن الجوزي: "كنتم خير الناس للناس"، 10 وقال ابن كثير: "المعنى أفم خير الأمم وأنفع الناس للناس"، 11 وقال النحاس: والتقدير على هذا: كنتم للناس خير أمة"، 12 وقال البغوي: "أي كنتم خير أمة للناس"، 13 وزاد أبو السعود الأمر توضيحاً فقال: "أي كنتم خير الناس للناس، فهو صريح في أن الخيرية بمعنى النفع للناس، وإن فُهم ذلك من الإخراج لهم ايضاً، أي أُخرجت لأجلهم ومصلحتهم".14 وهو المعنى الذي استوحاه الخطيب فقال: "من رسالة هذه الأمة أن لا تحتجز الخير لنفسها، ولا تستأثر به حين يقع ليدها، بل تبعل منه نصيباً تبرُ به الإنسانية كلها".

إن أمة هاتان أخص خصائصها لا يككن أن تحدها أرض، أو يختص بها مكان، بل لا بد أن تخرج إلى الناس، وتبلغهم رسالة الله إلى العالمين. فأي كلام بعد ذلك عن "دار إسلام" و"دار كفر"، أو "دار إسلام" و"دار حرب" - بالمعنى الجغرافي لهذين المصطلحين - إنما هو ضرب من التكلف وتضييق لآفاق الرسالة.

بل إن مفهوم "الأمة" في شرعنا لا يرتبط بالكم البشري أو الحيز الجغرافي أصلاً، وإنما يرتبط بالمبدأ الإسلامي، حتى وإن بجسد ذلك المبدأ في شخص واحد، ولذلك استحق إبراهيم عليه السلام وصف "الأمة" في القرآن الكريم، لقنوته لله وشكره لأنعمه: هإِإن إبراهيم كان أمة قانتاً لله حنيفاً ولم يك من المشركين شاكراً لأنعمه اجتباه وهداه إلى صراط مستقيمه (النحل: 120-121).

$$
\begin{aligned}
& 9 \\
& 10 \\
& 11 \\
& 12 \text { 13 القرطبي: الجامع لأحكام القرآن 171/4. } \\
& 13 \\
& 14 \\
& 15 \text { 1 } 15
\end{aligned}
$$


وقد أدرك بعض علمائنا الأقدمين المغزى الذي نقصد إليه هنا، فربطوا تلك التحديدات بإمكان إظهار الإسلام وأمن المسلمين فقط. فليست للإسلام حدود جغرافية، ودار الإسلام هي كل أرض يأمن فيها المسلم على دينه، حتى ولو عاش ضمن أكثرية غير مسلمة، ودار الكفر هي كل أرض لا يأمن فيها المؤمن على دينه، حتى ولو انتمى جميع اهلها إلى عقيدة الإسلام وحضارته.

قال الكاساني: "لا خلاف بين أصحابنا (الأحناف) في أن دار الكفر تصير دار إسلام بظهور أحكام الاسلام فيها". 16 أما دار الإسلام فقال القاضي أبو يوسف ومحمد بن الحسن: "تصير دار كفر بظهور أحكام الكفر فيها". 17 وروى ابن حجر عن الماوردي رأيا ذهب فيه إلى أبعد من ذلك، فاعتبر أن الإقامة في دار كفر يستطيع المسلم إظهار دينه فيها أولى من الإقامة في دار الاسلام، لما في ذلك من القيام بوظيفة جذب الناس إلى هذا الدين وتحسينه إليهم، ولو بمجرد الاحتكاك والمعايشة: "قال الماوردي: إذا قدر (المسلم) على إظهار الدين في بلد من بلاد الكفر، فقد صارت البلد به دار إسلام، فالإقامة فيها أفضل من الرحلة منها، لما يُترجى من دخول غيره في الإسلام". 18

\section{الانتصار والإيجابية}

ومما امتدح الله تعالى به عباده المؤمنين الإيجابية والانتصار لحقوقهم، ورفض البغي والظلم، وعدم الرضا بلمذلة والهوان. قال تعالى:

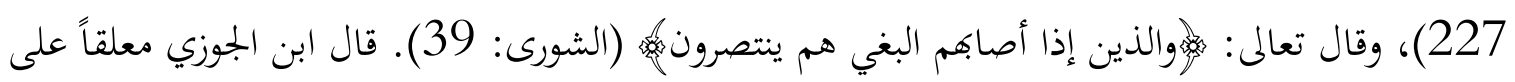
هذه الآية الأخيرة: "ليس للمؤمن أن يذل نفسه"، 19 وقال ابن تيمية: "... وضد الانتصار العجز، وضد

\begin{tabular}{|c|c|}
\hline \multicolumn{2}{|l|}{ الكاساني: بدائع الصنائع 131/7 } \\
\hline نفس المصدر والصفحة. & \\
\hline جر : فتح الباري 230/7. & \\
\hline ي: زاد المسير 122/7. & \\
\hline
\end{tabular}


الصبر الجزع، فلا خير في الصبر ولا في الجزع، كما نجده في حال كثير من الناس، حتى بعض المتدينين إذا ظلموا أو رأوا منكرا، فلا هم ينتصرون ولا يصبرون، بل يعجزون ويجزعون". 20 فأي رضا من المسلمين بالدّون، أو بالمواقع الخلفية، وأي سلبية وانسحاب من التفاعل الايجابي مع الوسط الذي يعيشون فيه يناقض مدلول هاتين الآيتين الداعيتين إلى الإيجابية والانتصار.

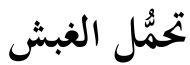

ولو اقتضت المشاركة الإيجابية تحمل نوع من الغبش الذى لا يمس جوهر العقيده وأساسيات الدين، فهو أمر مغتفر إن شاء الله، لأن تحقيق الخير الكثير المرجوِ متعذر بدونه، وليس هذا الأمر بجديد على الفقه الإسلامي، بل هو أمر قبله علماء الإسلام منذ غاية الحلافه الراشدة وبداية الملك، فقد وضع الواقع الجلديد أهل الخير أمام أحد خيارين: إما المشاركة الإيجابية مع قبول تنازلات يمليها واقع الظلم المتغلب، وإما السلبية والانسحاب وترك الأمة في أيدي الظلمة، فاختاروا الخيار الأول إدراكاً منهم لإيجابية الإسلام ومرونة تشريعاته. قال ابن تيمية مؤصِّلا هذا الأمر: "الواجب على المسلم أن يجتهد في ذلك بحسب وسعه: فمن وليَ ولاية يقصد بها طاعة الله وإقامة ما يمكنه من دينه ومصالح المسلمين، وأقام فيها ما يمكنه من ترك المحرمات،

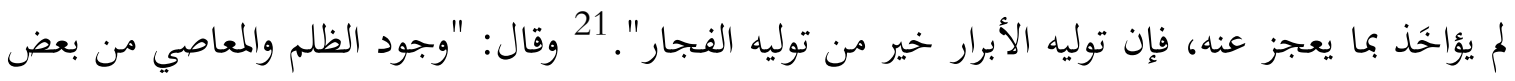
المسلمين وولاة أمورهم وعامتهم لا يمنع أن يشارَك فيما يعمله من طاعة الله". 22

ولو كان - رحمه الله - حيَّا الآن لأضاف: "بعض الكافرين وولاة أمورهم وعامتهم، تمشيًا مع منطق الموازنة الشرعية الذي تبناه، ومراعاة لتغير الوقائع.

وانسجامًا مع نفس المنطق تقبَّل ابن حجر سؤال الإمارة والحرص عليه - رغم في السنة عن ذلك -

إذا كانت حقوق المسلمين ومصالحهم معرضة للإهدار والضياع، فقال: "من قام بالأمر (الامارة) عند خشية

\begin{tabular}{|c|c|}
\hline ابن تيمية: التفسير الكبير 59/6. & 20 \\
\hline ابن تيمية: السياسة الشرعية، ص167. & 21 \\
\hline ابن تيمية: منهاج السنة 113/4. & 22 \\
\hline
\end{tabular}


الضياع يكون كمن أُعطي بغير سؤال، لفقد الحرص غالبًا عمن هذا شأنه، وقد يُغتفر الحرص في حق من تعين عليه لكونه يصير واجباً عليه". 23

\section{عبرة من الهجرة إلى الحبشة}

وتضمنت التجربة الإسلامية الأولى مثالاً على لجوء المسلمين إلى بلاد الكفر لحماية دينهم، هو الهجرة إلى الحبشة، ولذا المثال أهمية خاصة لأنه وقع في عصر الاستضعاف الشبيه بحال المسلمين الآن، كما أنه وقع في عهد التشريع، مما يضفي مغزى تأصيلياً على الدروس والعبر المستخلصة منه.

وقد وقعت حادثة في أثناء تلك الهجرة تحمل دلالة كبرى على ما يستطيع المسلمون المهاجرون فعله لحماية دينهم ورعاية مصالحهم، وكسب ودِّ غيرهم، واكتسابه للإسلام.

أورد الإمام أحمد بصيغ مختلفة وفي مواضع متعددة من مسنده تفاصيل هذه القصة الطويلة24 وخلاصتها أن قريشاً أرادوا مضايقة المسلمين المهاجرين إلى الحبشة، فبعثوا عمرو بن العاص وعبد الله بن أبي ربيعة محمّلَين بهدايا للنجاشي، ورشاوى لبطارقته، في محاولة لشراء الذمم من أجل تسليم المسلمين المستضعفين إليهم.

وتكلم عمرو وعبد الله بين يدي النجاشي فقالا: "أيها الملك: إنه قد صبا إلى بلدك منا غلمان سفهاء فارقوا دين قومهم، ولم يدخلوا فن دينك، وجاؤوا بدين مبتدع لا نعرفه نحن ولا أنت، وما بعثنا إليك أشرافُ قومهم من آبائهم وأعمامهم وعشائرهم لتردَّهم إليهم، فهم أعلى كمم عينًا، وأعلم بما عابوا عليهم وعاتبوهم فيه، فقالت بطارقته: صدقوا أيها الملك. فأسلمُهم إليهما فليردافم إلى بلادهم وقومهم". لكن النجاشي كان رجلاً عادلاً، ولم يكن ليقبل الحكم غيابياً على من لم يسمع حجته، فأمر بإحضار المسلمين "فلما جاءهم رسوله اجتمعوا ثم قال بعضهم لبعض: ما تقولون للرجل إذا جئتموه؟ قالوا: نقول والله ما علمنا وما أمَرَنا به

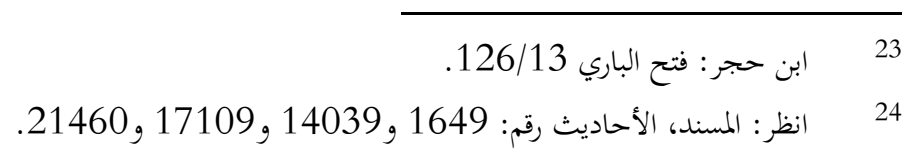


نبينا صلى الله عليه وسلم كائن في ذلك ما هو كائن. فلما جاؤوه وقد دعا النجاشي أساقفته فنشروا مصاحفهم حوله ليسأهم، فقال ما هذا الدين الذي فارقتم فيه قومكم ولم تدخلوا في ديني ولا في دين أحد من هذه الامم؟ قالت (أم سلمة راوية الحديث) فكان الذي كلمه جعفر بن أبي طالب، فقال: أيها الملك، كنا قوماً أهل جاهلية نعبد الأصنام ونأكل الميتة ونأتي الفواحش ونقطع الأرحام ونسيء الجوار ويأكل القوي منا الضعيف، فكنا على ذلك حتى بعث الله إلينا رسولاً منا نعرف نسبه وصدقه وأمانته وعفافه، فدعانا إلى الله تعالى لنوحده ونعبده ونخلع ما كنا نعبد نحن وآباؤنا من دونه من الحجارة والأوثان، وأمر بصدق الحديث وأداء الأمانة وصلة الرحم وحسن الجوار والكف عن المحارم والدماء، وهمانا عن الفواحش وقول الزور وأكْل مال اليتيم وقذف المصصنة، وأمرنا أن نعبد الله وحده لا نشرك به شيئا، وأمرنا بالصلاة والزكاة والصيام قالت: فعدّد عليه أمور الإسلام - فصدّقناه وآمنا به واتبعناه على ما جاء به. فعدا علينا قومنا فعذبونا ففتنونا عن ديننا ليددونا إلى عباده الأوثان. وأن نستحل ما كنا نستحل من الخبائث. ولما قهرونا وظلمونا وشقّوا علينا وحالوا بيننا وبين ديننا خرجنا إلى بلدك واخترناك على مَن سواك ورغبنا في جوارك ورجونا أن لا نُظلم عندك أيها الملك". وتوضح رواية أخرى أن جعفر لما دخل على النجاشي خالف العرف السائد الذي يقضي بالسجود للملك "فسلم و لمم يسجد، فقالوا له مالك لا تسجد للملك؟ قال إنّا لا نسجد إلا لله عز

وانتهت المناظرة بانتصار المسلمين، واقتناع النجاشي بعدالة قضيتهم، ورجع رسولا قريش من عند النجاشي شرّ مرجع "فخرجا من عنده مقبوحيْن مردوداً عليهما ما جاءا به" حسب تعبير أم المؤمنين أم

ثم توطدت العلاقة بين المسلمين وذلك الملك المسيحي إلى درجت أفم لجموا في الدعاء له بالنصر حين ظهر من ينازعه ملكه، قالت أم سلمة: "ودعونا الله تعالى للنجاشي بالظهور على عدوه، والتمكين له في بلاده".

وكانت النتيجة المنطقية لتلك العلاقة الوثيقة أن اعننق النجاشي الإسلام في غاية المطاف. 
بناء على ما اتضح من موازين الوحي، وخصائص أمة التوحيد، ومن المحددات المنهجية اللازمة ثم من تجربة المسلمين الأوائل في الحبشة، نستطيع التوصل إلى الخلاصات التالية:

إن وجود المسلمين في أي بلد يجب التخطيط له باعتباره وجوداً مستمراً ومتنامياً، لا باعتباره وجوداً طارئاً أو إقامة مؤقتة أملتها الظروف السياسية والاقتصادية في العالم الإسلامي ولا حجة في رجوع المهاجرين من الحبشة، لأن الهجرة كانت واجبة في صدر الدعوة وبناء المجتمع الجلديد، ثم سقط ذلك الوجوب بالفتح، كما قال صلى الله عليه وسلم: "لا هجرة بعد الفتح ولكن جهاد ونية". 25 كما أن رجوعهم كان مواصلة لهجرة جديدة، لأن مكة هي موطنهم.

ينبغي لأبناء الأقليات المسلمة أن لا يقيدوا أنفسهم باصطلاحات فقهية تاريخية لم ترد في الوحي مثل "دار الإسلام" و"دار الكفر". وعليهم أن ينطلقوا من المنظور القرآني: "إهإن الأرض لله يورثها من يشاء من

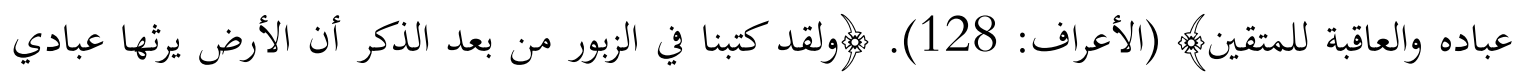
الصالحونهيم (الأنبياء: 105).

من واجب المسلمين أن يشاركوا في الحياة السياسية والاجتماعية باييجابية، انتصارا لحقوقهم، ودعما لإخوقم في العقيدة أينما كانوا، وتبليغا لحقائق الإسلام، وتققيقا لعالميته. ولقد قلنا إن ذلك "من واجبهم"، لأننا لا نعتبره مجرد "حق" يمكنهم التنازل عنه، أو "رخصة" يسعطم عدم الأخذ بها.

كل منصب أو ولاية حصل عليها المسلمون بأنفسهم، أو أمكنهم التأثير على من فيها من غيرهم، تُعد مكسبا لمم من حيث تحسين أحوالهم، وتعديل النظم والقوانين التي تمس صميم وجودهم، ولاسيما التي لا تنسجم مع فلسفة الإسلام الأخلاقية. ومن حيث التأثير على القرارت السياسية ذات الصلة بالشعوب

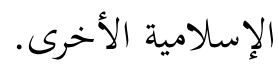

$$
25 \text { صحيح البخاري، كتاب الجهاد، الحديث 2575. وصحيح مسلم، كتاب الإمارة، الحديث 3468. }
$$


كل ما يعين على تحقيق هذه الغايات النبيلة من الوسائل الشرعية فهو يأخذ حكمها ويشمل ذلك تقدم المسلم لبعض المناصب السياسية، وتبّي أحد المترشحين غير المسلمين - إذا كان أكثر نفعاً للمسلمين، أو أقل ضرراً عليهم - ودعمه بالمال، فقد أباح الله تعالى بِرَّهم وصلتهم دون مقابل، فكيف إذا ترتب على لى ذلك مردود واضح ومصلحة متحققة. وفي تفسير ابن العربي للفظ "القسط" ما يمكن الاستئناس به.

إن انتزاع المسلمين لحقوقهم في بلد يمثلون أقلية فيه، وتفاعلهم الإيجابي مع أهل البلد الأصليين، يقتضي منهم تشاوراً وتكاتفاً واتفاقاً في الكليات، وتعاذراً في الجزئيات والخلافيات. ولنا في سلفنا من المهاجرين إلى الحبشة أسوة حين اجتمعوا وتشاوروا حول أمثل الصيغ للرد على الموقف الحرج.

يحتاج أبناء الأقليات المسلمة إلى ترسيخ الايمان بالله، وتدعيم الثقة بالإسلام، حتى لا يدفعهم التفاعل مع غيرهم إلى تنازلات تمس أساس الدين مجاراة لعرف سائد أو تيار جارف. وفي رفض جعفر السجود للنجاشي - كما فعل خصماه وكما يقضي العرف - أسوة في هذا السبيل.

تحتاج الأقليات المسلمة إلى حسن التعبير عن حقائق الاسلام الخالدة، ونظام قيمه الإنساني الرفيع، كما فعل جعفر في خطبته البليغة التي أوجز فيها أمهات الفضائل الاسلامية، وأوضح الفرق بينها وبين الحياة الجاهلية. وبذلك لا يكسب المسلمون تعاطف الناس فقط، بل يكسبون الناس أنفسهم للالتحاق بركب

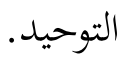

إن فن الاقناع وعلم العلاقات العامة لمما دور يحسن الانتباه له. فالكلام الذي ختم به جعفر خطبته يدخل في هذا السياق: "خرجنا إلى بلدك واخترناك على من سواك ورغبنا في جوارك ورجونا أن لا نظلم عندك أيها الملك". وبه نغتم هذه الملاحظات التي نرجو أن يجد فيها طالب الحق ما يعينه على حسن تصور الحكم الشرعي في هذا الأمر، وتجد فيها الأقليات الإسلامية ما يرفع عنها الحرج، ويدفعها إلى مزيد من الإيجابية والتضحية في خدمة الإسلام وحمله إلى العالمين. وبالله التوفيق، وهو الهادي إلى أقوم طريق. 